\title{
ANÁLISE FUNCIONAL DAS TRADUCCIÓNS EN LINGUAS EN PROCESO DE NORMALIZACIÓN: O CASO DA TRADUCCIÓN DO COMIC EN GALEGO
}

\author{
Por \\ CARSTEN SINNER
}

\section{RESUMEN}

A traducción de cómics, no caso do galego xoga un papel moi importante xa que o seu obxectivo é sobre todo normalizar o uso da lingua galega nas xeracións novas e familiariza-la xuventude coa norma. A contribución pretende unha análise ben polo miúdo dunha traducción galega de Asterix comparándoa co orixinal francés e coa traducción española.

\section{PALABRAS CLAVE}

Traducción, cómics, Astérix, normalización, galego, norma.

\section{ABSTRACT}

In the case of the Galician language, the translation of comics is quite important, because it contributes to the normalization of use of the Galician language and allows young readers to become familiar with the norm.

«CUADERNOS DE ESTUDIOS GALLEGOS», Tomo XLIX, Fascículo 115, Santiago 2002. 
The article focusses on an analysis of the Galician translation with the French original and a Spanish version of the text.

\section{KEYWORDS}

Translation, comics, Asterix, normalization of language use, Galician, norm.

\section{0.- INTRODUCCIÓN}

As traduccións para as linguas en proceso de normalización responden a unhas necesidades diferentes do que as traduccións que se fan, por exemplo, ás linguas nacionais. Esta contribución pretende facer unha análise ben polo miúdo dunha traducción galega de Astérix comparándoa co orixinal francés e coa traducción española. En casos coma o do galego, que durante moito tempo non contou cunha norma fixada, a traducción adquire unha importancia moi especial, pois a literatura en lingua galega, ademais de formar parte da normalización da lingua, contribúe a que a norma sexa recoñecida e espallada entre a poboación, aínda non moi acostumada a ve-la súa lingua escrita. A traducción de cómics, por conseguinte, xoga un papel moi importante xa que o seu obxectivo é sobre todo normaliza-lo uso da lingua galega nas xeracións novas e familiariza-la xuventude coa norma ${ }^{1}$. Unha crítica das traduccións de cómics, por todo iso, ten que estar baseada tanto nunha análise orientada no texto de partida (unha comparación co texto de partida) como nunha análise orientada no texto de chegada (cf. Reiß 1971), considerando aspectos externos ó proceso de traducción e avaliando a eficacia do texto de chegada como ferramenta normalizadora.

\footnotetext{
${ }^{1}$ Os cómics naturalmente tamén son lidos por adultos e segundo Spillner (1972:29) desempeñan un papel sociolingüístico moi importante, sen embargo son unha das literaturas máis lidos polos nenos e a xuventude.
}

«CUADERNOS DE ESTUDIOS GALLEGOS», Tomo XLIX, Fascículo 115, Santiago 2002. 


\section{1.- O PAPEL DA TRADUCCIÓN NO PROCESO DE NORMA- LIZACIÓN}

A traducción para o galego, lingua en proceso de normalización, ten outros fins que, por exemplo, a traducción para linguas coma o alemán, o francés ou mesmo o español, pois trátase de traduccións que responden claramente á necesidade de poñer á disposición dos lectores obras en lingua galega que antes non había ou que só había en grafías non estandardizadas e en edicións baratas ou menos atractivas en comparación coa oferta editorial en español. A traducción en Galicia, pois, responde á esixencia do obxectivo normalizador de posibilita-la lectura en galego normativo para familiariza-la xente, e en primeiro lugar a xuventude, coa norma e facer que ler en galego sexa a normalidade e non a excepción, para o cal é necesario que haxa unha oferta interesante, e non limitada de máis, de obras en galego. Existe, polo tanto, unha clara diferencia funcional entre a traducción para unha lingua en vías de normalización -ou «en vías de convertirse en lingua de cultura» (cf. Esser 1986 e 1990)-, para a cal constitúe un factor normalizador moi importante, e a traducción para unha lingua coma o español que, en xeral, responde sobre todo a cuestións de tipo económico. Un dos argumentos máis repetidos en contra da traducción de obras estranxeiras xa traducidas ó castelán é que sería malgastar cartos facer unha traducción ó galego cando xa existe traducción castelá. O maior problema para o mercado da traducción galega consiste, daquela, no feito de os galegos comprenderen castelán ${ }^{2}$. As traduccións nas linguas cooficiais compiten directamente coas traduccións en castelán, que gracias a teren un mercado moito maior pódense permitir meirandes gastos de producción, o que moitas veces se traduciría en traduccións e edicións máis coidadas, etc., se non fose polas subvencións concedidas ás editoriais que publican nas linguas minoritarias ${ }^{3}$. Sen embargo, o fomento das traduccións nas linguas cooficiais ten acadado gran protagonismo nos últimos tempos. Especialmente en Cataluña criticouse duramente a política de fomento da lingua cooficial por ser «antidemocrática», argumentando que non recoñece a pluralidade cultural e lingüística ${ }^{4}$.

\footnotetext{
${ }^{2}$ Cf. Meyer (1998:102) sobre «as reaccións do tipo, pero se isto xa o lin en castelán».

${ }^{3}$ Cf. Meyer (1998:100) ó respecto.

${ }^{4}$ Cf. Foro Babel (1998); para Galicia, cf. Jardón (1993:72-75).
} 


\section{2.- A TRADUCCIÓN DE ASTÉRIX}

A traducción de cómics é unha rama moi marxinada dentro da teoría da traducción; existe abundancia de bibliografía sobre múltiples aspectos dos cómics, pero case non hai estudios sobre a súa traducción (Schmitt 1997: 619). Para a análise da traducción para o galego escollemos un episodio de Astérix por ser considerado unha seria de alta calidade dentro do sector do cómic e parte integrante do xénero das belas letras (Schmitt 1997: 622), por dirixirse tanto a lectores mozos como adultos, por oferecela posibilidade de comparalo cunha ampla gama de traduccións noutras linguas, especialmente noutras linguas románicas, e por existir un episodio que tematiza España: Astérix en Hispania (Astérix en Hispanie). A tematización dunha realidade ben coñecida polos lectores galegos, pero vista desde a perspectiva do veciño francés, necesariamente implica certos problemas de traducción á hora de adapta-lo texto para uns lectores, naturalmente, moito máis familiarizados coa cultura española cós lectores do texto orixinal ${ }^{5}$.

\section{3.- ANÁlISE ORIENTADA NO TEXTO DE PARTIDA DA TRA- DUCCIÓN GALEGA DE ASTÉRIX EN HISPANIA}

Non abordaremos aquí os problemas semánticos da traducción dos nomes propios nos cómics nin as dificultades que presenta a traducción de xogos de palabras, pois ámbolos dous son uns dos poucos temas relacionados coa traducción dos cómics que si se teñen estudiado ${ }^{6}$. Na análise orientada no texto de partida da traducción galega de Astérix en Hispania, atopamos poucos elementos que merecen ser criticados. Hai varios erros de traducción que se deben, supostamente, á non percepción dos matices do texto orixinal ou, quizá, ó simple feito de que o traductor non reparase nos detalles en cuestión. Trátase, entón, dalgúns erros de traducción que, ademais, non interfiren na boa percepción da versión galega polo lector.

\footnotetext{
${ }^{5}$ Cf. Vermeer (1987:542) quen fala de mudanzas dos contidos en vistas á interpretación da súa importancia na cultura de chegada.

${ }^{6}$ Cf., ó respecto, Jacqmain/Cole (1970), Stoll (1974), Rothe (1974) e Grassegger
} (1985)

«CUADERNOS DE ESTUDIOS GALLEGOS», Tomo XLIX, Fascículo 115, Santiago 2002. 
De «Je suis fils de chef», na traducción faise (1) ${ }^{7}$ «Eu son fillo do xefe» (páx. 12) ${ }^{8}$; o uso do artigo determinado altera o efecto da frase no contexto dado. Na versión francesa nótase claramente que o neno que está a falar é arrogante e cre formar parte dunha «casta» diferente; en galego pérdese esa noción. Durante un ataque dos galos ós romanos, un dos galos berra, referíndose ós romanos: «Laissez-les moi» (páx. 13). En vez de traducilo por «¡Deixádemos!», o traductor pon (2) «deixádeme», o significado altérase e a escena perde toda a gracia. Na páxina 31 atopamos un erro moi raro, «Réveillez-vous!» tradúcese por (3) «iErguédevos!» en troques de «iEspertade!». A única razón que xustificaría o troco do verbo sería o feito de querer introducir, intencionadamente, o verbo «erguerse» para acostumar a aqueles que normalmente empregan un castelanismo tan enraizado coma «levantar» («iLevantádevos») ó uso da palabra galega.

\section{4.- ANÁLISE FUNCIONAL -ORIENTADA NO TEXTO DE CHEGADA- DA TRADUCCIÓN DE ASTÉRIX EN HISPANIA}

\section{1.- As funcións do texto}

É un factor moi importante que, na súa versión orixinal, Astérix é un texto expresivo (cf. Reiß 1976; Schmitt 1997: 622) pero que, ó noso ver, en galego (como texto traducido) ademais de formar parte, naturalmente, do mesmo tipo de textos expresivos, tamén ten aspectos claramente operativos (segundo a clasificación de Reiß 1976), pois é un medio para acadar que a norma sexa recoñecida e espallada entre a poboación e especialmente para que as xeracións novas se familiaricen con ela: trátase dunha traducción subvencionada pola Xunta de Galicia (Consellería de Educación e Ordenación Universitaria, Dirección Xeral de Política Lingüística) o que debería garantir que se tratase dunha obra traducida con fins normalizadores. As diferencias funcionais dos dous textos, orixinal e traducción, pódense representar da seguinte maneira:

\footnotetext{
${ }^{7}$ Os exemplos extraídos da versión galega van con números en negra.

${ }^{8}$ As indicacións de páxinas son idénticas nas edicións analizadas, por iso nas citas non indicámo-las tres diferentes edicións.
}

«CUADERNOS DE ESTUDIOS GALLEGOS», Tomo XLIX, Fascículo 115, Santiago 2002. 


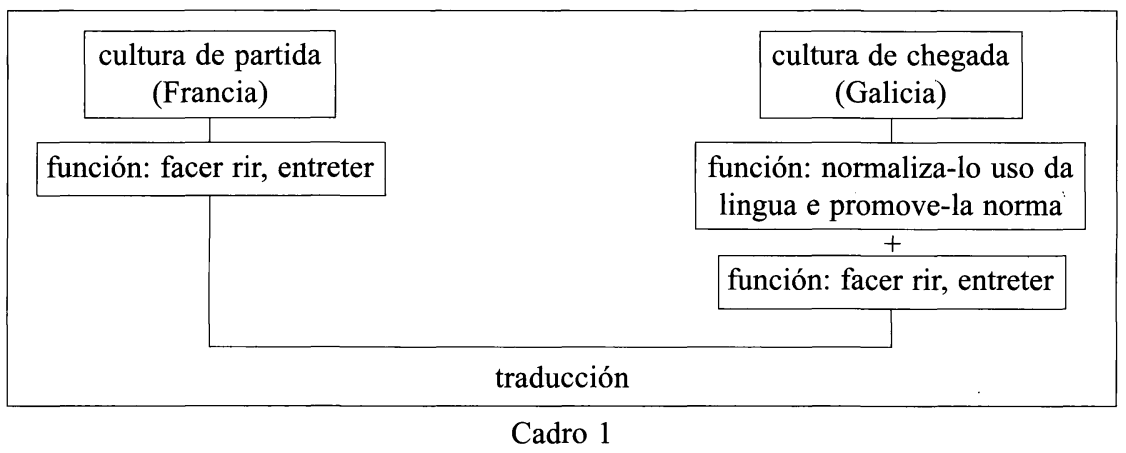

Por isto, adicareime á análise da traducción tanto baixo o aspecto da traducción dun texto expresivo como tamén baixo o aspecto dun texto operativo, isto é, considerando a función que desempeñará na cultura de chegada. $\mathrm{O}$ texto de chegada terá que satisfacer varias condicións: Ten que considerar ou respecta-la norma sen resultar artificial, achegándose, sempre que sexa posible, á lingua falada pola comunidade. Ten que ser o máis galego posible, isto é, idiomático, para os lectores se recoñeceren na lingua empregada no texto e se identificaren con ela, pero, para melloralo coñecemento da norma e fortalece-lo uso das formas recomendadas ha de tentar substituír formas non atendidas pola norma, pero que forman parte da lingua oral normal e que son comúns entre os galegofalantes.

Dado o feito que non só a cultura de chegada, senón tamén a función do texto de chegada é diferente que no caso do texto de partida (cf. cadro 1), parécenos que os factores extralingüísticos no proceso da traducción posiblemente provocaron manipulacións a nivel denotativo e / ou connotativo que precisan dunha explicación extralingüística, para seren, se ben non se poidan xustificar, polo menos comprendidas a través dunha explicación dos procesos que levaron á manipulación. Unha traducción adecuada desde o punto de vista funcional non necesita conservar todo o contido do senso nin tódalas peculiaridades estilísticas do texto orixinal, pero si debe transmitir correctamente a principal función comunicativa da traducción (Korotov 1994: 48). Ademais das dificultades resultantes da pretensión normalizadora, naturalmente hai para o traductor outras dificultades «normais» que o lector nin sequera debe notar (cf. Ekmann 1995: 285). 


\section{2.- Cuestións de imprenta}

Non imos tratar a fondo problemas específicos da traducción de cómics como son o lettering (escritura das letras, ou á man ou á máquina), a posible necesidade de manipulación dos debuxos, a desnacionalización temática ${ }^{9}$, etc., pero hai algúns aspectos que merecen ser tratados. O lector non debe darse conta da mediación dunha cultura diferente da súa polo traductor, isto é, non debería haber vestixios do texto de partida en calquera forma. Sen embargo, a traducción galega chama a atención por un factor moi negativo respecto das esixencias do lector normal: atópanse, en varias ocasións, bocadillos baleiros, o que provoca a impresión de que o traductor deixou sen traducir parte do texto orixinal. O lector acaba por crer que lle falta información (cf. páxs. 9; 27; 28; 30). Sentirase traizoado e pensará que está a ler unha traducción mal feita. Resulta sorprendente constatar que nas viñetas da versión orixinal tales bocadillos non se atopan: introducíronse na edición española para engadir comentarios adicionais, e como se empregaron os mesmos debuxos para a imprenta, tamén están na versión galega, pero sen texto. Nalgúns casos, sen embargo, realmente falta parte do texto orixinal, o que non ten máis explicación que, como se trata de partes tipograficamente diferentes do resto do texto (elementos gráficos nos bocadillos, etc.), ó introduci-los textos traducidos simplemente esquecéronse de poñelos $(36,38)$. Como na traducción galega os textos non se introduciron á man, como é o caso da versión francesa, houbo unha reducción notable da expresividade da traducción respecto ó orixinal. O mellor exemplo atópase na páxina 20 da traducción, onde no orixinal se ve claramente, pola letra empregada e polos pentagramas, que se trata de música cantada (e mal cantada) e na traducción pérdese a información adicional por non estaren os pentagramas ${ }^{10}$. O mesmo ocorre no caso das frases acompañadas por flores, para expresar que se din nun tono moi doce; na versión galega faltan as flores e pérdese a información adicional.

${ }^{9}$ Cando, por exemplo, unha historia ocorre nos EE.UU., no orixinal, e en ningún sitio concreto, na traducción.

${ }^{10} \mathrm{Cf}$. Schmitt (1997:633 e 639) sobre o mesmo problema na traducción alemana, e sobre a representación gráfica dos chamados soundwords e da prosodia por medio da letra introducida á man.

«CUADERNOS DE ESTUDIOS GALLEGOS», Tomo XLIX, Fascículo 115, Santiago 2002. 


\section{3.- Relación de signos verbais e nonverbais}

Os cómics son textos semioticamente moi complexos nos cales os signos verbais e non-verbais se completan e determinan mutuamente; un cómic perde a súa coerencia, e posiblemente a súa aceptabilidade como texto, se os constituíntes verbais e non-verbais deixan de conxugar (Schmitt 1997: 619). Un caso obvio de perda de coerencia atópase na páxina 16, onde Obélix vai mercar peixe e, co peixe na man, di (4) «iCollerei este!». En francés é «Je prends celui-ci», e en galego sería de esperar «Collo este», pois xa ten o peixe na man. En galego, o emprego do futuro non é idiomático para accións inmediatas. O traductor, definitivamente, orientouse na versión castelá («Tomaré este»). En castelán tampouco sería de esperar aquí o uso dun tempo verbal de futuro, pero de feito, o traductor (tamén traductor da versión catalana) é catalán e, ou ten interferencias do catalán, ou simplemente ten certa preferencia polo tempo verbal do futuro, que é un trazo típico do castelán falado en Cataluña (cf. Sinner 2000). Sexa como for, trátase dun catalanismo bastante chocante para o lector galego. Hai outro caso parecido onde sería posible pensar tanto en galicismo coma en catalanismo: $O$ francés «Nous venons nous demander s'il vous serait possible de...» (páx. 26) é traducido por (5) «Vímosvos pedir se sería posible que...», igual que na versión castelá que pon «Venimos a pediros si sería posible que...». Tanto en galego coma en castelán, e a diferencia do catalán e do francés, o normal sería dicir «preguntar» en troques de «pedir», pois «demander» pódese traducir, segundo o contexto, por ámbalas dúas.

\section{4.- Idiomaticidade}

A falta de idiomaticidade é un problema xeral do texto analizado, especialmente por non alcanza-la oralidade nin a espontaneidade que esixe a linguaxe do cómic, normalmente máis oral ca escrita, e por empregar expresións que no contexto en que se atopan non significan nada, que levan a malentendidos ou teñen connotacións non contidas no contexto orixinal ${ }^{11}$.

\footnotetext{
${ }^{11}$ Segundo Spillner (1972:29) a linguaxe do cómic é lingua «case oral».
} 


\subsection{1.- Interferencia do francés}

Ás veces é resultado de interferencia do francés ou de o traductor non se ter afastado suficientemente do texto orixinal. A construcción francesa «Si on en achetait, pour changer?» (páx. 5), referíndose Astérix ó peixe, leva ó traductor á construcción non idiomática (6) «E se mercasemos, para variar un pouco?», deixando fóra «peixe» que se esperaría en galego: «¿E se mercasemos peixe, para variar un pouco?». De «Quands nous te rendrons ton fils» faise (7) «Cando che devolvamos o teu fillo» (páx. 8), sobrando o posesivo na traducción galega. Da frase francesa «Il y a en Gaule quelques garnison désœuvrées» (páx. 8), na traducción faise (8) «Hai na Galia algunhas gornisóns desocupadas», sendo a sintaxe a dunha pregunta, pero non a dunha frase enunciativa galega: o lector galego esperaría unha frase do tipo «Na Galicia hai». A frase (9) «iTi es repugnante!» (páx. 12), en absoluto galega polo emprego do pronome, motivado, claramente, polo texto orixinal «Tu es écœurant», provoca outra interpretación, pois parece por unha énfase no «ti» que no orixinal non se percibe. No orixinal o fillo do xefe da tribo ibera di: «je retiens ma respiration» (páx 33) para obrigar ós outros a faceren o que el manda. Na traducción lese (10) «eu conteño a miña respiración»; en galego, nin o emprego do pronome persoal nin o do pronome posesivo é idiomático e ha de atribuírse á estructura do francés.

A traducción de «Tu me laisseras parler...» é (11) «iDéixame falar...!» (páx. 13), frase que un falante galego emprega cando o seu discurso se ve interrompido pola intervención do oínte e coa que esice que o deixen continuar, equivalente a «Non me interrumpas», mentres que en francés queda ben claro que se trata dunha proposta do tipo «déixame falar a min», «será mellor que fale eu». Cando o xefe da tribo cae do escudo no chan, alcanzado por un peixe que alguén da tribo lle tirou, berra, vermello de rabia, (12) «¿Quen fixo isto?» (páx. 19), o que resulta pouco espontáneo en semellante situación en galego, pois sería de esperar un berro como «¿Quen foi?» como na versión castelá: «¿Quién ha sido?». O traductor galego, aquí, queda moi preto da estructura francesa: «Qui a fait ça?».

Atópase a construcción (13) «somos máis razoables ca eses dous fenómenos» (páx. 37) que non é incorrecta, pero queda moi artificial, raro, en vez dunha construcción xenuinamente galega coma, por exemplo, «eses boas pezas», etc. A comparación coa versión francesa fai ver de onde vén:

«CUADERNOS DE ESTUDIOS GALLEGOS», Tomo XLIX, Fascículo 115, Santiago 2002. 
«nous sommes plus raisonnables que ces deux phénomènes». Máis tarde, un bandido de estradas di: (14) «Somos bandidos de estradas importantes e, ¿que queredes?, pero nós tamén aproveitamos a temporada turística» (páx. 40). «¿Que queredes?» resulta moi forzado e o sentido do enunciado non queda claro. A comparación coa versión francesa («Nous sommes des bandits de grand chemin et que voulez-vous, nous aussi nous profitons de la saison touristique») aclara que unha traducción como «que se lle vai facer» ou «sentímoscho ben» sería máis acertada.

\subsection{2.- Outros tipos de falta de idiomaticidade}

En varias ocasións, a falta de idiomaticidade parece te-las súas raíces na traducción castelá que, con certeza, se empregou á parte do orixinal. Ademais de casos coma os referidos nos exemplos (4) e (5), hai casos en que non está claro de qué tipo de influencia se pode tratar: De difícil explicación é, por exemplo, a constante posposición do nome como vocativo como (15) «mira Astérix» (p. 25), mentres que en galego o vocativo vai sempre ó principio. Tamén resulta rara a omisión do vocativo ${ }^{12}$ necesario en galego: (16) «Mañá separarémonos de Mochacamisa y Pocochaleque» (páx. 41), traducción do francés «Demain nous quittons mon cher Surlepondavignon y Danson». Podería esperarse unha construcción como «Mañá separarémonos, querido Mochacamisa». Ás veces, a falta de idiomaticidade só se pode atribuír a unha decisión deliberada ou a un erro do traductor -ou quizá do corrector-: que o xefe da tribo ibera, louco de rabia polo secuestro de seu fillo, diga (17) «iSe te tivese no meu poder, romano, ordenaría que te fritisen en aceite de oliva!» (páx. 8) resulta pouco espontáneo e pouco crible na situación dada, pois non resulta o suficientemente oral, coma, por exemplo, unha frase como «iComa te colla, romano...!». Noutra escena, Obélix e mais Pepe están a discutir e Astérix dilles: (18) «¡Acabade dunha vez e deixade de discutir!» (páx. 30). En francés non se atopa esta reduplicación de significado do tipo deixar / acabar («Ce n'est pas bientôt fini vos discussions?») que non ten razón de ser en galego e que resulta bastanto estraña. A construcción «por sorte que», como por exemplo en (19) «iPor sorte que aínda somos máis razoables [...]!» (páx. 37) non é galega. En galego, úsase «por

\footnotetext{
${ }^{12}$ Cf. Hammermüller (1997) sobre a distinción de «vocativo» e «apelema».
} 
sorte, aínda somos máis razoables» ou «que sorte que aínda», pero a expresión empregada non existe; parece unha mestura non acertada das dúas formas existentes.

Así pois, a sensación xeral é a de pouca idiomaticidade, o que é negativo tendo en conta que se trata de facer unha traducción que esperte o interese do lector. $\mathrm{O}$ feito de $\mathrm{xa}$ haberen problemas de idiomaticidade nas partes onde non houbo que altera-lo texto por mor da normalización é problemático, pois fai que o texto resulte bastante chocante e, por riba, pouco atractivo.

\section{5.- Erros lingüísticos / cara á norma}

\subsection{1.- Incorreccións}

Son constantes as incorreccións lingüísticas non atribuíbles a interferencias. Por exemplo, o traductor emprega lleísmos que segundo a norma non son correctos: (20) «[...] imponlle[s] respecto ós seus homes e temor ós seus inimigos» (páx. 4) ${ }^{13}$. O mesmo erro atópase máis veces, por exemplo (21) «non dicirlle[s] nada ós nosos xefes» (páx. 22) e (22) «voulle[s] preguntar a eses dous» (páx. 32). Na versión francesa, César di sobre a súa coroa de loureiro chafada: «J'ai dù m'endormir dessus, un soir, par inadvertance» (páx. 6). O traductor galego emprega un xerundio en vez dun adxectivo («Debín quedar durmindo»] o que sería incorrecto no contexto dado, pois César non quedou a dormir enriba da coroa de loureiro, senón que adormeceu enriba dela, e fíxoo, como el mesmo comenta, sen darse conta («par inadvertance»). O correcto sería, por tanto, «Debín quedar durmido». (23) «Beliscou a miña orella» tamén é incorrecto, pois é «beliscar en algo», por tanto debería ser «beliscoume na orella» (páx. 7). A construcción francesa «Dites, on ne pourrait pas installer, mes amis et moi, dans votre maison roulante» (páx. 28) tradúcese (24) «Oiga [sic] non poderíamos instalarnos, os meus amigos e máis [sic] eu, na vosa casa rodante». Á parte do castelanismo «oiga» (cf. 4.4.2.), temos aquí un caso de falta de concordancia, pois en galego «vosa» é plural, non é o tratamento de cortesía de singular. Por tanto, tería que ser «Oia, non poderiamos instalarnos na súa casa».

${ }^{13}$ Cf. Fernández Rei (1991:80) sobre a zona de llelo e a distinción de número no dativo. Noutro caso, o traductor pon «lles» en troques de «lle»: «non lles pasará nada [ó fillo]» (páx. 8) 


\subsection{2.- Castelanismos}

A introducción de castelanismos por vía de interferencia provocou «unha situación singular entre moitos galego-falantes na actualidade e que é un dos síntomas máis contundentes da anormalidade lingüística en que vive [...] [o idioma galego]: o emprego de castelanismos profundamente instalados socialmente, non por descoñecemento da norma nin sequera porque a utilización da voz propiamente galega puidese provocar dificultades de comprensión para o interlocutor, senón para non rachar o vínculo afectivo-comunicativo entre ambos». (Silva Valdivia 1991: 37). Hai abundantes exemplos de tales castelanismos. En galego non corresponde á norma emprega-lo verbo «asistir» como sinónimo de «presenciar» ou «observar unha escena»; só se asiste a un acto público ou a unha ceremonia. O traductor, sen embargo, usa a construcción (25) «algúns iberos que asisten á escena» (páx. 5), sexa pola estructura francesa («assistent à la scène»), sexa pola construcción castelá, pois en castelán a construcción é correcta ${ }^{14}$. A palavra «xove» é outro exemplo dunha palabra que non é considerada pola normativa pero que se emprega no texto: (26) «ó noso xove protexido» (páx. 19). Trátase, sen embargo, dunha palabra usada ata a nivel oficial, pois existe o chamado "carné xove» promovido pola Xunta de Galicia, o que, se ben non xustifica o emprego, polo menos pode explicalo. «Xove» non se atopa nos diccionarios e segundo o DXLI (1993: 1030) é forma incorrecta, sendo correcto «novo» (adx.) e «mozo» (s. e adx.) $)^{15}$. Hai demasiados castelanismos coma para describilos todos ben polo míudo, a seguir atópase unha lista dos máis importantes; os castelanismos van en negra:

(27) «Apoderádevos del» (páx. 7) [en troques de «coller», «prender» ou «capturar», pois apoderarse só funciona con cousas].

(28) «Acabo de herdar unha leiriña que quixera arreglar» (páx. 23) [en vez de «amañar» ou «arranxar»].

${ }^{14}$ Cf. a séptima acepción de «asistir» no diccionario da Real Academia Española (DRAE 1992: 212): concurrir a una casa o reunión, tertulia, curso, acto público, etc. No diccionario da Real Academia Galega (DRAG 1997: 122) non aparece esta acepción do verbo.

${ }^{15}$ Sen embargo, aínda atópase no Diccionario Xerais da Lingua (DXL 1986:923) con esas mesma acepcións.

«CUADERNOS DE ESTUDIOS GALLEGOS», Tomo XLIX, Fascículo 115, Santiago 2002. 
(29) «¿Oiga, non poderiamos instalarnos [...]?» (páx. 28) [A forma do imperativo do verbo «oir» é «oia»].

(30) «iOu sexa, que estás de novo entre nós!» (páx. 33) [en troques de «así que», «isto é», etc.].

(31) «por error» (páx. 47) [en vez de «por erro»].

Tamén é castelanismo (ou quizá galicismo) o emprego do futuro en vez do condicional para indica-la posibilidade que unha cousa ten de se realizar: (32) «¡Xa será mala sorte se non chego a distraer a súa atención» (páx. 39) en troques de « ¿Xa sería mala sorte se non chego a distraer a súa atención» para "Ce sera bien le malheur si je n'arrive a distraire leur attention»; en castelá, sen embargo, é correcto o futuro: «iYa será mala suerte $[\ldots] \gg$.

\subsection{3.- Erros de ortografía e tipografía}

Os erros de ortografía e de tipografía son, sen esaxerar, unha verdadeira traxedia nunha obra que ten como propósito acostuma-los nenos á ortografía galega, pois a repetición e a presencia da palabra escrita é unha instancia que lle fai recordar ó falante os principios da norma referencial (Kremnitz 1990: 96). Un caso especialmente grave é o uso indistinto de (33) xabarís e xabaríns (páx. 4), pois podería confundir ós lectores non acostumados á gramática normativa e parecer dúas formas de plural de xabarín, palabra que se usa no resto do episodio. Xabarís sería o plural de xabaril, variante recomendada pola norma. O caso da palabra xabarín en si xa é problemático, posto que xabarín non foi a variante recomendada pola norma, pero que é a que acabou por adaptarse gracias a un programa xuvenil moi exitoso da Televisión de Galicia, «Xabarín Club» ${ }^{16}$. Entre os erros ortográficos, pesa especialmente o da acentuación xeralizada de «mais» na conxunción copulativa «e mais» coma en (34) «Idéfix e máis eu» (páxs. 9 e 20), (35) «os meus amigos e máis eu» (páx. 28) e (36) «Pepe e máis eu» (páx. 38) ${ }^{17}$, pois velo escrito con acento pode confundir

\footnotetext{
${ }^{16}$ A variante centro-oriental xabaril foi a variante rexional recomendada pola norma; xabarín era a forma occidental tamén admitida, porco bravo é a oriental. Os diccionarios dan xabarín como variante (cf. DXLI 993:953), pero considerándoo "forma incorrecta» (DXLI 1993:1030).

${ }^{17}$ Cf. RAG (1983:133).
}

«CUADERNOS DE ESTUDIOS GALLEGOS», Tomo XLIX, Fascículo 115, Santiago 2002. 
ós lectores máis ca outros erros. No tocante á ortografía de palabras compostas sen guión, coma (37) «forza sobre humana» (páx. 40) en troques de «sobrehumana» (cf. páx. 4) pódese dicir o mesmo.

Hai moitos máis exemplos de erros de ortografía e de tipografía ou de falta de palabras pero non paga a pena entrar máis neste eido que xa de por si non precisa máis comentarios. Velaquí unha lista de erros: (38) «unha palabra [de] máis e sería unha catástrofe!» (páx. 13); (39) «iUn refen é un refén!» [en vez de «¡Un refén! ¡É un refén!»] (páx. 14); (40) «todos os día[s]» (páx. 22); (41) "condenado a [=á] escravitude» (páx. 22); (42) «Ollan para min os dous [e] bótanse a rir» (páx. 24), (43) ¿Que se come [...]! [en vez de ¿Que se come?]; (páx. 25) (44) «para contar ó[s] meus netos moitas [=moitos] longos seráns» (páx. 30); (45) «hai que pasar a fronteira directamente» [en vez de «discretamente» para o francés «discrètement»] (páx. 28), etc.).

\subsection{4.- Cuestións de rexistro}

Tamén hai problemas de rexistro, coma o uso moi vulgar e totalmente fóra de lugar de «gabacho» nunha cartela explicativa, esto é, nun contexto non oral, introducida, amais, polo traductor sen razón: (46) «E non o uroqueador, como din a miúdo os gabachos, por error [sic!]» (páx. 47).

\section{5.- MANIPULACIÓNS DO TEXTO E PROBLEMAS RESUL- TANTES}

\section{1.- Manipulacións para face-lo texto máis galego ou introducir referencias a Galicia}

\subsection{1.- Erros de lóxica}

Son particularmente graves os erros que van en contra da lóxica histórica e que por regra xeral resultan da tentativa do traductor de introducir, á forza e sen reparar nos efectos contraproducentes, referencias a Galicia no episodio de Astérix en Hispania. Falando do estado da estrada, Asterix di, na versión francesa: «Elle est drôle d'état, la route» (páx. 34). Na versión galega, exclama: (47) «Estes accesos a Galicia non os acaban nin no século XX...». O lector posiblemente se decatará da contradicción histórica, pois supostamente estamos no ano 45 antes de Xesús (cf. páx. 5) e Astérix non pode saber da maneira de máis tarde se contaren os anos. 
Como consecuencia desta primeira modificación, o traductor ten que alterar outras pasaxes do texto. Faille responder ó pequeno ibero que (48) «é preferible vir polo corredor do norte, antes que atravesar as terras quentes da Castela», caendo, en consecuencia, no absurdo de manda-los heroes da historia desde Francia por Galicia (e entón posiblemente tamén por Portugal) a Montilla. Ata os menos interesados en historia ou xeografía entre os lectores españois se darán conta desta falta de coherencia provocada polo traductor, pois polo propio texto sábese que a aldea do pequeno ibero atópase preto de Monda (=Montilla), é dicir na rexión de Córdoba, en Andalucía, no sur da España ${ }^{18}$.

\subsection{2.- ¿Compensación de perdas na traducción?}

Dado o feito de que nos bocadillos só hai lugar restrinxido para a inclusión de texto, todo tipo de unidades lingüísticas adicionais adquire transcendencia particular, pois normalmente trátase de elementos que na lingua de chegada teñen que usarse, mentres que no orixinal non teñen a mesma necesidade ou porque no orixinal a información era, por exemplo, expresada por medio doutra categoría gramatical (cf. Spillner 1972: 31). Á parte das diferentes estructuras das dúas linguas implicadas, tamén pode responder á vontade de modifica-lo texto por mor de compensar perdas noutros sitios ou por introducir información adicional, sexa cal for a razón de a engadir. Na crítica da traducción ten que considerarse que a compensación non é posible sen intervencións noutros sitios do texto que entón poden parecer non ter motivación ou xustificación ningunha. Sen embargo, a inserción das referencias a Galicia non parece responder á tentativa de compensación, pois se ben os anacronismos forman parte do concepto das historias de Astérix, atópanse tantas ampliacións de contido do mesmo tipo que os casos referidos non poden ter que ver coa compensación de perdas noutros sitios; xa se pode falar, pois, de tematización intencionada ${ }^{19}$. Aínda máis descarado cós casos descritos é o exemplo da

\footnotetext{
${ }^{18}$ Dedúcese pola información dada na páxina 5, primeira páxina do episodio («César acaba de vencer ós últimos superviventes en Munda», indicando nunha nota que se trata da cidade de Montilla) e na páxina 6 (Hai unha pequena aldea, non lonxe de Munda, que ten uns habitantes que se negan a integrarse no mundo romano e que continúan resistindo...). Montilla atópase a $44 \mathrm{~km}$ de Córdoba.

${ }^{19}$ Cf. Fuchs / Reitberger (1973:245) sobre os anacronismos intencionados en Astérix.
} 
páxina 35, onde Astérix e Obélix se atopan cuns xitanos que, naturalmente só na versión galega, din a seguinte tolería: «Nós imos a Santiago á festa do apóstolo». Pode resultar gracioso a primeira vista, pero é, ó noso entender, una inserción inxustificable no argumento do episodio, e un atentado contra o saber de calquera lector galego quen, sen dúbida, saberá o suficiente sobre a historia do apóstolo Santiago ou sobre a mesma cidade de Santiago como para quedar alucinado. Nos cómics, as indicacións de lugares, cidades, etc., normalmente son tratadas como noutros tipos de literatura, isto é, os lugares e accións non se transladan para a cultura de chegada, mais conservan as referencias á cultura de partida ou ó mundo real (Schmitt 1997: 642). Por isto, sorprende aínda máis que na traducción galega se encontren tantas mudanzas deste tipo. Non se debe esquecer que un lector tamén se pode ofender coa traducción e que é posible que por culpa da ampliación se poida producir «una gran interferencia en la recepción del mensaje» (Mayoral 1994: 92).

Co desexo de facer que a traducción sexa o máis galega posible, o traductor tamén introduce expresións e frases que remiten para a realidade galega, o cal resulta, tamén, bastante irritante. Faise falar a persoas caracterizadas como as xentes do sur da Península Ibérica con expresións ou maneiras de falar que fan clara referencia á cultura galega, igual có mesmo Xulio César (que despois de secuestrarlle o fillo ó xefe da tribo ibera dille: (49) «E se non queredes que cho devolvamos coma o polbo á feira, tes que darnos probas da túa boa conducta» (páx. 8)) ou ós piratas que case sempre aparecen nas historias de Astérix. Nas poucas frases pronunciadas polos piratas no seu barco aparecen referencias a Galicia: (50) «O mezmiño ca unha miñoca de Fizterra ${ }^{20} »$ (páx. 26), e nunha conversación entre dous romanos na Galia lemos: (51) «iParéceme que se digo a César que ti non me axudaches a recuperar o refén, vannos tocar unha muiñeira ós dous nese circo» (páx. 12).

$\mathrm{Na}$ tentativa de introducir palabras ou construccións consagradas pola norma, pero non empregadas pola xente na rúa quizá se inspire a frase xa mencionada de Xulio César (52) «cho devolvamos coma o polbo á feira» (páx. 8). A construcción «normalmente» empregada na Galicia ten o castelanismo «pulpo» («pulpo á feira»), e «polbo» aínda resulta total-

${ }^{20}$ A ortografía (mezmiño, Fizterra) débese ó suposto ceceo dun dos piratas. 
mente artificial, especialmente nunha situación tan marcadamente oral coma a do texto, onde César lle está berrando ó xefe da tribo, ríndose del. A necesidade de facer que as palabras reintroducidas, ou que se queren reintroducir na fala do pobo, sexan aceptadas fai necesario que se comece nalgún lugar. $\mathrm{O}$ uso de «polbo» no cómic, por moi artificial que soe no inicio, é totalmente xustificable desde a perspectiva da función normalizadora do texto; que se faga dunha maneira tan pouco elegante, empregando o termo nunha situación onde queda tan fóra de lugar, é sorprendente. Sen embargo, como unha traducción como a de Astérix está, supostamente, pensada para perdurar, as seguintes xeracións xa non atoparán estraña a frase.

\section{2.- Outras manipulacións}

Outro tipo de manipulación constatada no texto analizado é a inserción de comentarios que fan referencia á actualidade, probablemente para face-lo texto máis divertido. Os engadidos menos nocivos para a percepción da traducción son, como a referencia á canción do verán de 1996, Macarena, que se introduce nunha escena de danza cos «nomadas» (páx. 35). Ó esquecerse a canción co tempo, a referencia ó texto da mesma non producirá interferencia na comprensión do texto, polo que esa manipulación aínda pode darse por boa. Sen embargo, pode estrañar a calquera lector que coñeza a canción e saiba que o orixinal francés é dos anos sesenta, pois posiblemente terá a sensación de ler unha traducción que non pode ter moita relación co orixinal.

Se por unha parte, por mor da normativización ou da aceptación da norma, se admiten elementos que imposibilitan que a lectura, polo menos de momento, sexa fluída, parece estraño que amais se poñan tantas pasaxes que levan ó envellecemento prematuro da traducción porque farán que quede anticuada e pasada de moda en pouco tempo. Refírome ós elementos inseridos que fan referencia a acontecementos importantes para o desenvolvemento económico de España como a Exposición Universal de Sevilla en 1992 (mencionada como EXPO: (53) «As estradas están mellorando con isto da EXPO» (páx. 41) ou o Tratado de Maastricht firmado en Maastricht o día 7 de Febreiro de $1992^{21}$ ((54) «¿Pero que

${ }^{21}$ Os criterios de converxencia para dito Tratado tiñan que ser satisfeitos o día 1 de Xaneiro de 1992.

«CUADERNOS DE ESTUDIOS GALLEGOS», Tomo XLIX, Fascículo 115, Santiago 2002. 
esperades aquí todos vós? - ¡É por causa dos lexionarios romanos que vixían a fronteira...! ¡Mentres non se senten a falar en Maastricht!» (páx. 28). Mentres que o orixinal, despois de décadas, aínda é divertido e fai rir, a traducción galega dentro de moi poucos anos xa non será nin divertida nin (e isto é peor ) intelixible, pois en poucos anos, como moi tarde despois do seguinte tratado importante que veña substituí-lo Tratado de Maastricht, o que acontecerá, con certeza, coa ampliación da Unión Europea, ninguén saberá o que é (ou era) Maastricht, e despois da seguinte Expo, posiblemente xa neste mesmo ano 2000, coa Exposición Universal de Hannover en Alemaña, non se entenderá a alusión á Expo de Sevilla do ano 1992.

Estas últimas alteracións do texto tamén remiten a unha temática ben importante, pero moitas veces esquecida no proceso da traducción: a cuestión do destinatario. "Como se sabe, a tradução depende do seu Destinatário, ou seja, da pessoa (ou das pessoas) para quem se faz o trabalho, assim como do objectivo que a tradução tenta atinguir. É mister que o tradutor saiba quem será o 'consumidor' da sua obra. $\mathrm{O}$ factor destinatário é uma das noções-chave na teoria da comunicação moderna» (Korotov 1994: 52). Tendo en conta esta noción-clave, necesariamente hanse cuestiona-las razóns das alteracións feitas. Se co texto se pretende atraer ós lectores novos, as referencias a Maastricht, por exemplo, constitúen claros factores de interfencia na mensaxe, pois non se entenderán. Se é ós lectores adultos, o tipo de linguaxe empregado e a calidade da edición (refírome ós bocadillos baleiros, por exemplo) dificilmente serán aceptados por eles. A perda de calidade pode levar a que cómics que no orixinal son atractivos para lectores adultos, como é o caso de Astérix, na traducción soamente o sexan para nenos (Schmitt 1997: 646).

\section{6.- CONSIDERACIÓNS FINAIS}

Astérix en Hispania parécenos unha traducción mal feita e pouco lograda, porque é chea de erros de traducción e de erros no mesmo galego, castelanismos, infraccións da normativa e léxico non atendido pola mesma. É ben visible que a traducción está demasiado preto da versión francesa, e que se orientou, tamén, na versión en castelán, cousa que non lle foi 
vantaxoso. É unha edición pouco coidada, pois ademais dos erros léxicos e morfosintácticos, atópanse tamén moitísimos erros de ortografía e tipografía que fan da lectura unha verdadeira mágoa. O obxectivo de face-lo texto máis galego custou caro, por unha banda, porque as manipulacións se notan moito, pola outra, porque algunhas das alteracións non necesarias provocan un envellecemento prematuro da traducción, que quedará obsoleta dentro de moi poucos anos. Dunha publicación subvencionada pola Xunta sería de esperar que coidase máis os aspectos mencionados. Ó noso ver, non soamente é importante que haxa Astérix en galego, a calidade da traducción tamén é importante e debería coidarse máis se se quere contribuír a espalla-la norma e conseguir que se respete e, sobre todo, que se tome en serio.

\section{CORPUS ANALIZADO}

UDERZO, A. / RENÉ G. (1969): Astérix en Hispanie. Neuilly-Sur-Seine: Dargaud.

UDERZO, A. / RENÉ G. (1997): Astérix en Hispania. Traducción de Antonio Pichel. Barcelona / Vigo: Grijalbo / Dargaud / Galaxia.

UDERZO, A. / RENÉ G. (1998): Asterix en Hispania. Traducción de Víctor Mora. Barcelona: Grijalbo / Dargaud.

\section{REFERENCIAS BIBLIOGRÁFICAS}

DRAE $=$ Real Academia Española $\left({ }^{21} 1992\right):$ Diccionario de la lengua española. Madrid: Espasa Calpe.

DRAG = Real Academia Galega (1997): Diccionario da Real Academia Galega. A Coruña / Vigo: Real Academia Galega / Edicións Xerais / Editorial Galaxia.

DXL = Ares Vázquez, María Carme et al. (1986): Diccionario Xerais da Lingua. Vigo: Edicións Xerais de Galicia.

«CUADERNOS DE ESTUDIOS GALLEGOS», Tomo XLIX, Fascículo 115, Santiago 2002. 
DXLI = Ares Vázquez, María Carme et al. ( $\left.{ }^{4} 1993\right)$ : Diccionario Xerais da Lingua Ilustrado. 4 edición, corrixida e actualizada, con novas láminas de léxico e vocabulario de dúbidas. Vigo: Edicións Xerais de Galicia.

EKMANN, B. (1995): «Schwierigkeiten beim Schreiben eines witzigen Untertitels. Motzki im dänischen Fernsehen», in: Thorsten Unger / Brigitte Schulz / Horst Turk (eds.): Differente Lachkulturen? Fremde Komik und ihre Übersetzung. Tübingen: Gunter Narr Verlag, 283-297.

ESSER, U. (1986): «O galego, lingua en elaboración», Grial 93, 334-343.

ESSER, U. (1990): Die Entwicklung des Galizischen zur modernen Kultursprache. Eine Fallstudie zur aktuellen Sprachplanung. Bonn: Romanistischer Verlag.

FERNÁNDEZ REI, F. ( $\left.{ }^{2} 1991\right)$ : Dialectoloxía da lingua galega. Vigo: Edicións Xerais de Galicia.

Foro Babel (1998): «Por un nuevo modelo de Cataluña», El País 20.6.1998. [Tamén en: Fòrum Babel (1999): El nacionalisme i les llengües de Catalunya. Ed. por Antonio Santamaría. Barcelona: Ediciones Áltera, 288-295].

FUCHS WOLFGANG, J. / REINHOLD REITBERGER, C. (1973): Comics. Anatomie eines Massenmediums. Reinbek bei Hamburg: Rowohlt.

GRASSEGER, H. (1985): Sprachspiel und Übersetzung. Eine Studie anhand der Comic-Serie Asterix. Tübingen: Stauffenburg Verlag.

HAMMERMÜLLER, G. (1997): “'Fräulein' oder 'Frau' - 'Menina' despois de casar?», in: Helmut Lüdtke /Jürgen Schmidt-Radefeldt (eds.): Linguistica contrastiva. Deutsch versus Portugiesisch - Spanisch -Französisch. Tübingen: Gunter Narr Verlag, 25-36.

JACQMAIN, M. / HERMAN C. (1970): "Astérix à la conquête de l'Europe», Babel XVI / 1, 4-12 e 20. 
JARDÓN, M. (1993): La «normalización lingüistica», una anormalidad democrática. El caso gallego. Madrid: Siglo Veintiuno de España Editores.

KOROTOV, KONSTANTIN S. (1994): «Sobre alguns problemas de avaliação de tradução», Lusorama 24, 64-55.

KREMNITZ, G. (1990): «Wirkungsweisen repressiver Sprachpolitik dargestellt am Beispiel des Katalanischen in der Franco-Zeit», Zeitschrift für Katalanistik 3, 90-102.

MAYORAL, R. (1994): «La explicitación de información en la traducción intercultural», in: Amparo Hurtado Albir (ed.): Estudis sobre la traducció. Castelló: Publicacions de la Universitat Jaume I, 73-96.

MEYER, F. (1998): «O papel das traduccións no caso Galicia-Alemaña na actualidade», Grial 137, 99-107.

RAG = Real Academia Galega / Instituto da Lingua Galega ( $\left.{ }^{2} 1983\right):$ Normas ortográficas e morfolóxicas do idioma galego. Vigo: Real Academia Galega / Instituto da Lingua Galega.

REIß, K. ( $\left.{ }^{3} 1993\right):$ Texttyp und Übersetzungsmethode: der operative Text. 3., unveränderte Auflage. München: Groos.

ROTHE, W. (1974): «Asterix und das Spiel mit dem Namen», Die Neueren Sprachen 73, 241-261.

SCHMITT, PETER A. (1997): «Comics und Cartoons: (k)ein Gegenstand der Übersetzungswissenschaft?», in: Horst W. Drescher (ed.): Transfer. Übersetzen-Dolmetschen-Interkulturalität. Frankfurt/M. et al.: Peter Lang, 617-662.

STOLL, A. (1974): Asterix, das Trivialepos Frankreichs. Die Bild- und Sprachartistik eines Bestseller-Comics. Köln: DuMont.

«CUADERNOS DE ESTUDIOS GALLEGOS», Tomo XLIX, Fascículo 115, Santiago 2002. 
SILVA VALDIVIA, B. (1991): «Tipoloxía das manifestacións de contacto lingüístico en Galicia. Algunhas consideración», Cadernos de lingua 4 / 2, 27-38.

SINNER, C. (2000): «Frecuencia de perífrasis verbales como índice de variación lingüística», Revista de Lingüística Teórica y Aplicada 38, (en prensa).

SPILLNER, B. (1972): «Kontrastive Analysen auf der Grundlage von 'comic strips'», in: Gerhard Nickel (ed.): Papers from the International Symposium on Applied Contrastive Linguistics, Stuttgart, October 1113, 1971. Bielefeld: Cornelsen, Velhagen \& Klasing, 27-41.

VERMEER, HANS J. (1987): «Literarische Übersetzung als Versuch interkultureller Kommunikation», in: Alois Wierlacher (ed.): Perspektiven und Verfahren der interkulturellen Germanistik. Akten des I. Kongresses der Gesellschaft für Interkulturelle Germanistik. München: Iudicium-Verlag, 541-549. 